\title{
Chromatographic studies of the carbohydrate components of gastric and salivary mucopolysaccharides
}

\author{
J. SCHRAGER \\ From the Group Laboratory, Royal Infirmary, Wigan
}

EDITORIAL SYNOPSIS These chromatographic studies suggest that the carbohydrate components of the gastric and salivary mucopolysaccharides contain glucose, galactose, mannose, and fucose. The gastric secretions of 12 patients with gastric carcinoma showed a marked increase in glucose.

An attempt has been made in our laboratory to study the human gastric mucopolysaccharides and their secretory patterns in normal and pathological conditions of the gastric mucosa. The mucopolysaccharides of the salivary secretions have also been investigated. At one stage of our investigation paper chromatography was used extensively. The results obtained are to be reported in this communication. The procedure for the fractional aspirations of the gastric secretion has already been described. (Schrager, 1961)

\section{METHODS AND MATERIALS}

Histamine and intravenous insulin were used as secretory stimulants. The gastric and salivary secretions were collected simultaneously and independently in ice-cooled test tubes. Eight aspirations of gastric secretions and eight specimens of saliva were obtained for every fractional gastric analysis. Adequate quantities for the routine investigations were removed from each specimen. The remaining gastric secretion and saliva were each pooled in separate containers and immediately stored in a deep freeze refrigerator overnight, thawed out, and centrifuged for 30 minutes in the refrigerated centrifuge (M.S.E. Super-Speed 40) at 10,000 r.p.m. to remove solid particles and cell debris. The supernatant was treated with diastase (total hexose: diastase $-1: 20$ by weight) at $37^{\circ} \mathrm{C}$. for five hours followed by dialysis at $4^{\circ} \mathrm{C}$. against running water for five days and distilled water until free of chloride. The dialysed secretion was concentrated under reduced pressure at $30^{\circ} \mathrm{C}$. to about one twentieth of its volume and hydrolysed with $2 \mathrm{~N} \mathrm{H}_{2} \mathrm{SO}_{4}$ at $100^{\circ} \mathrm{C}$. for two hours in sealed ampoules. The hydrolvsate was neutralized with $\mathrm{Ba}(\mathrm{OH})_{2}$, centrifuged, the supernatant evaporated to dryness in vacuo, and redissolved in a minimal quantity of water for chromatography on sheets of Whatman no. 1 paper $(18 \times 22.5$ inches $)$. At a later stage of our investigation we used Dowex-50 suspended in 0.05 $\mathrm{N}$ hydro- chloric acid as a catalyst for the hydrolysis (Anastassiadis and Common, 1958). The sugars were developed by the ascending method using the solvent $n$-butanol: pyridine: water $(6: 4: 3)$. Each chromatogram underwent three ascending developments, the paper was dried and replaced in fresh solvent for each development which lasted 36 hours. The total development of the chromatogram took about five and a half days. The sugars were detected with aniline hydrogen phthalate reagent (Partridge, 1949). Latterly we used the following reagent: $1.2 \mathrm{~g}$. of p-anisidine, $1.7 \mathrm{~g}$. of phthalic acid, $10 \mathrm{mg}$. of $\mathrm{SnCl}_{2} \mathrm{H}_{2} \mathrm{O}$ in $100 \mathrm{ml}$. of ethanol (Moore, Spackman, and Stein, 1958). Between 100 and $200 \mathrm{ml}$. of gastric secretion and saliva is needed, depending on the amount of the mucopolysaccharides present, in order to obtain the concentration of the individual sugars necessary for chromatography.

The gastric secretion of 36 controls, consisting of 16 healthy volunteers and 20 patients who had no history of gastric symptoms or any present gastrointestinal complaints (Table I), 60 patients with duodenal ulcers (Table II), 18 patients with gastric ulcers (Table III), and

\section{TABLE 1}

SEX AND AGE OF 36 CONTROLS

\begin{tabular}{lllllllll}
\multicolumn{1}{c}{ Age Groups $(y r)}$. \\
\cline { 2 - 8 } Sex & $0-20$ & $20-30$ & $30-40$ & $40-50$ & $50-60$ & $60-70$ & $70-80$ \\
\hline Male & Nil. & 4 & 2 & 5 & 4 & 2 & Nil. \\
Female & $11(18$ yr.) & Nil. & 6 & 4 & 8 & Nil. & Nil. \\
& $(18$ & & & & &
\end{tabular}

TABLE II

SEX AND AGE OF 64 PATIENTS WITH DUODENAL ULCER

\begin{tabular}{|c|c|c|c|c|c|c|c|}
\hline \multirow[t]{2}{*}{ Sex } & \multicolumn{2}{|c|}{ Age Groups (yr.) } & \multirow[b]{2}{*}{$30-40$} & \multirow[b]{2}{*}{$40-50$} & \multirow[b]{2}{*}{$50-60$} & \multirow[b]{2}{*}{$60-70$} & \multirow[b]{2}{*}{$70-80$} \\
\hline & $0-20$ & $20-30$ & & & & & \\
\hline Males & 1 (19 yr.) & 5 & 9 & 20 & 9 & 3 & 2 \\
\hline
\end{tabular}


TABLE III

SEX AND AGE IN 16 PATIENTS WITH GASTRIC ULCER

\begin{tabular}{|c|c|c|c|c|c|c|c|}
\hline \multirow[t]{2}{*}{$\operatorname{Sex}$} & \multicolumn{2}{|c|}{ Age Groups (yr.) } & \multirow[b]{2}{*}{$30-40$} & \multirow[b]{2}{*}{$40-50$} & \multirow[b]{2}{*}{$50-60$} & \multirow[b]{2}{*}{$60-70$} & \multirow[b]{2}{*}{$70-80$} \\
\hline & $0-20$ & $20-30$ & & & & & \\
\hline $\begin{array}{l}\text { Male } \\
\text { Female }\end{array}$ & & & & $\begin{array}{l}3 \\
1\end{array}$ & $\begin{array}{l}3 \\
2\end{array}$ & $\begin{array}{l}5 \\
1\end{array}$ & 1 \\
\hline
\end{tabular}

TABLE IV

SEX AND AGE IN 12 PATIENTS WITH CARCINOMA OF STOMACH

\begin{tabular}{|c|c|c|c|c|c|c|c|}
\hline \multirow[t]{2}{*}{ Sex } & \multicolumn{2}{|c|}{ Age Groups (yr.) } & \multirow[b]{2}{*}{$30-40$} & \multirow[b]{2}{*}{$40-50$} & \multirow[b]{2}{*}{$50-60$} & \multirow[b]{2}{*}{$60-70$} & \multirow[b]{2}{*}{$70-80$} \\
\hline & $0-20$ & $20-30$ & & & & & \\
\hline $\begin{array}{l}\text { Male } \\
\text { Female }\end{array}$ & & & & $\begin{array}{l}1 \\
2\end{array}$ & 2 & 2 & $\begin{array}{l}1 \\
3\end{array}$ \\
\hline
\end{tabular}

12 patients with carcinoma of the stomach (Table IV) were investigated. Only 15 controls, 20 patients with duodenal ulcer, eight patients with gastric ulcer, and four patients with gastric carcinoma provided sufficient quantities of saliva for chromatography.

\section{RESULTS AND CONCLUSIONS}

Our results do not support the common assumption that the human gastric mucopolysaccharides contain uronic acid. The chromatograms of the 120 gastric and 50 salivary secretions showed no uronic acid (Figs. 1-6), but when uronic acid was added to gastric secretion and hydrolysed it did appear on the chromatograms (Fig. 4). A solution of $1 \%$ chondroitin sulphate, treated as described above and chromatographed, also showed uronic acid (Fig. 4). These experiments indicate that our method of hydrolysis frees uronic acid and does not destroy it.

All our chromatograms invariably showed zones corresponding to glucose and mannose in addition to galactose and fucose. Glucose and mannose as components of human gastric mucopolysaccharides and glucose as a component of the salivary mucopolysaccharides are not mentioned in the literature as far as I know. Werner (1953) states that he could find no glucose in human gastric mucopolysaccharides after incubation with saliva and dialysis. Our investigation shows that both glucose and mannose are present in all the chromatographed secretions. The indentification of glucose and mannose is based on the following: 1 The identity of the $R_{F}$ values given with glucose and mannose standards. 2 The addition of glucose and mannose to the hydrolysates results in the intensification of the spots but not in the appearance of further ones. 3 Glucose disappears in the chromatograms of

NORMAL GASTRIC SECRETIONS

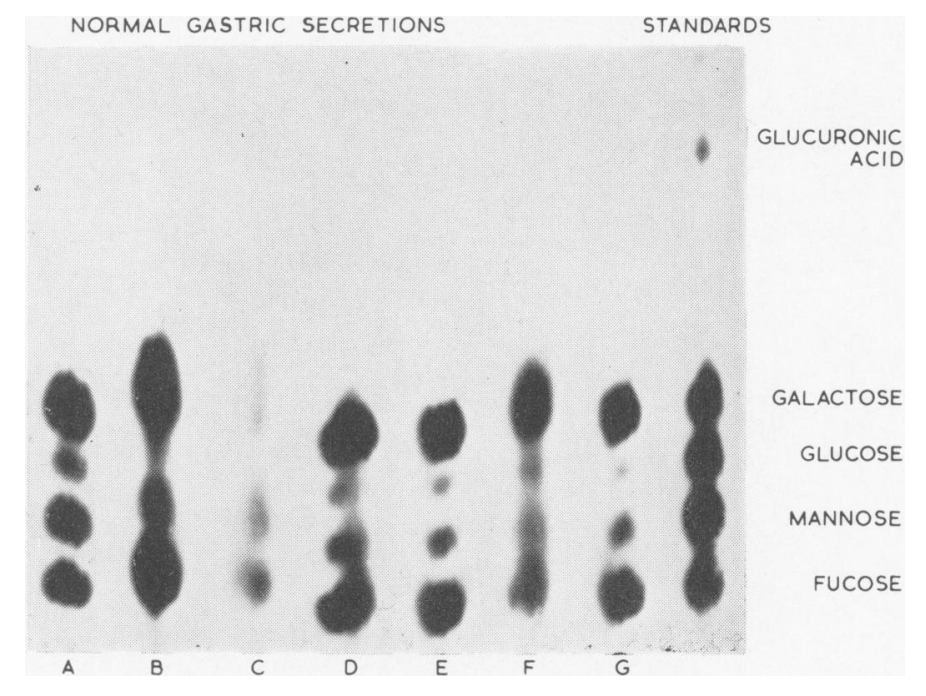

FIG. 1.

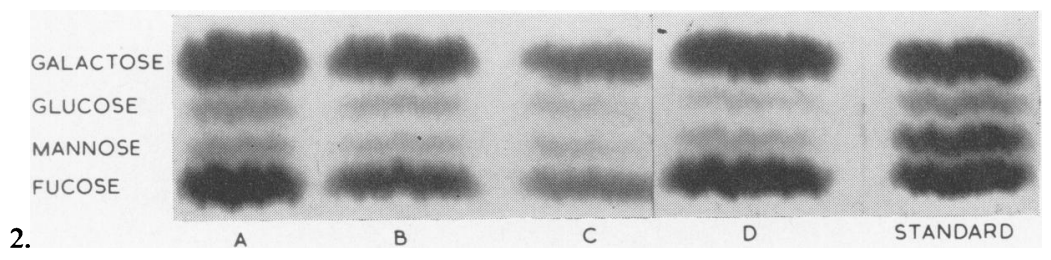




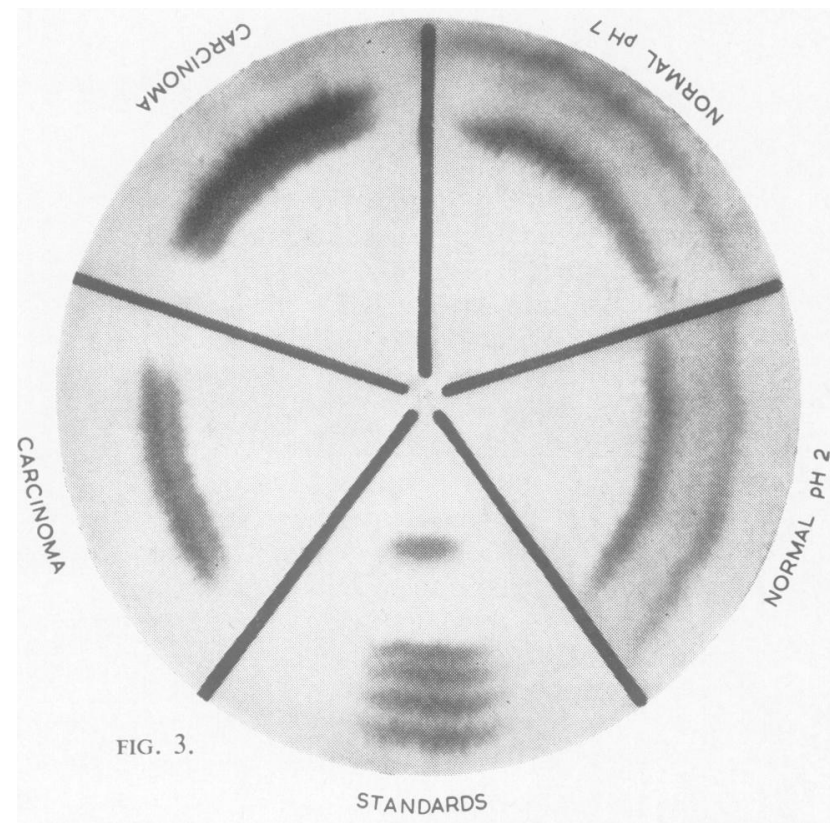

STANDARDS

NORMAL GASTRIC NORMAL GASTRIC SECRETION SECRETION
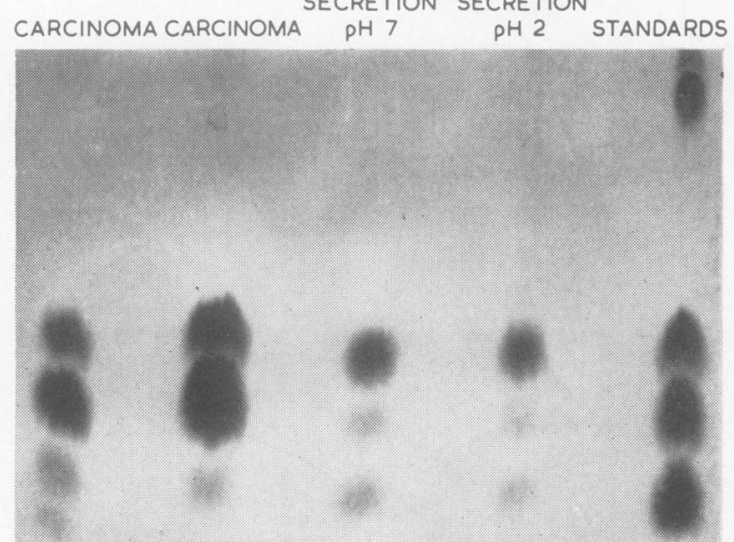

STANDARDS

FIG. 5 .

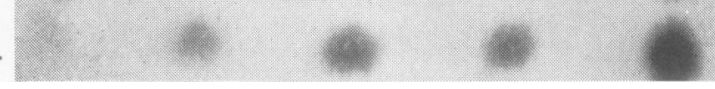

\section{GLUCURONIC $A C I D$}

FROM PATIENTS WITH

STANDARD 2 CARCINOMA OF THE STOMACH STANDARD I

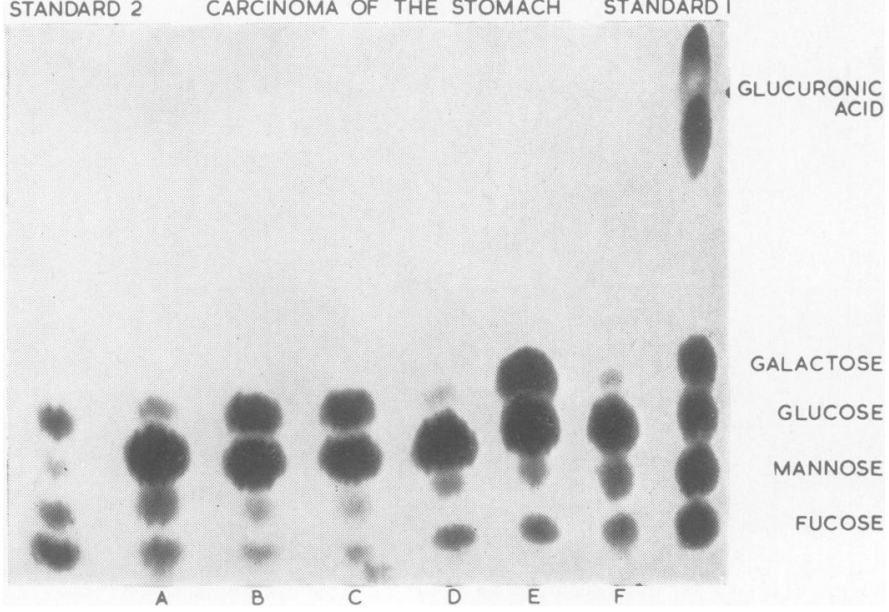

GALACTOSE

GLUCOSE

MANNOSE

FUCOSE

GALACTOSE

GLUCOSE

MANNOSE

FUCOSE

GALACTOSAMINE

GLUCOLACTONE

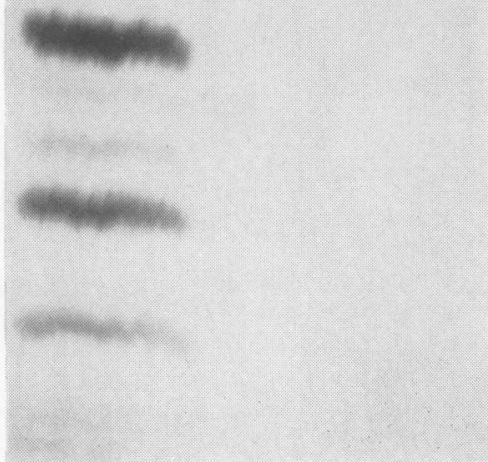

FIG. 4.

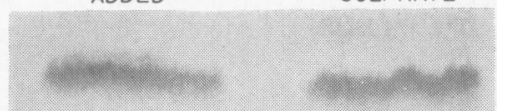


gastric secretion hydrolysate incubated with glucose oxidase.

The presence of mannose has been demonstrated in other forms of human mucopolysaccharides, namely in duodenal (Dische, Di Sant'Agnese, Pallavicini, and Youios, 1959) and bronchial mucopolysaccharides (Brogan, 1959), and in canine submaxillary saliva (Dische, Pallavicini, Kavasaki, Smirnow, Cizek, and Chien, 1962).

Glucose was demonstrated in all the salivas investigated (Fig. 2) as well as in all the gastric secretions from our controls and from patients suffering from duodenal ulcer and gastric ulcer after three redevelopments, each lasting 36 hours. It was not found on circular horizontal chromatograms after a 10-hour development (Fig. 3). Quantitative determination of the sugars, using Wilson's (1959) elution method, show the ratios of galactose: glucose $=$ $10: 1$ to $10: 2$. In order to separate the small quantities of glucose from the larger quantities of galactose prolonged and several redevelopments are needed.

The carbohydrate components of the gastric mucopolysaccharides of patients with carcinoma of the stomach show quantitative ratio differences from those of all other gastric secretions investigated. In the latter galactose and fucose are the predominant sugars. The secretion of the malignant stomach revealed a marked decrease in galactose and a great increase in glucose, the galactose being often reduced to a mere trace (Fig. 6). Horizontal circular chro- matograms of gastric secretion of patients with gastric carcinoma always show glucose (Fig. 3). The large quantities of glucose present are separated even after one short development lasting 10 hours.

The quantitative relationship of the carbohydrate components of the gastric mucopolysaccharides is being further investigated.

I wish to thank the Medical Research Sub-Committee of the Manchester Regional Hospital Board for a financial grant. My thanks are also due to Mrs. J. M. Goodger for secretarial assistance.

\section{REFERENCES}

Anastassiadis, P. A., and Common, R. H. (1958). Liberation of hexosamine, hexuronic acid, and hydroxyproline from tissues by resin hydrolysis. Canad. J. Biochem., 36, 413-424.

Brogan, T. D. (1959). The carbohydrate complexes of bronchial secretion. Biochem. J., 71, 125-131.

Dische, Z., Di Sant'Agnese, P., Pallavicini, C., and Youlos, J. (1959). Composition of mucoid fractions from duodenal fluid of children and of adults. Arch. Biochem., 84, 205-223.

_-, Pallavicini, C., Kavasaki, H., Smirnow, N., Cizek, L. J., and Chien, S. (1962). Influence of the nature of the secretory stimulus on the composition of the carbohydrate moiety of glycoproteins of the submaxillary saliva. Ibid., 97, 459-469.

Moore, S., Spackman, D. H., and Stein, W. H. (1958). Chromatography of amino acids on sulforated polystyrene resins. Anal. Chem., 30, 1185-1190.

Partridge, S. M. (1949). Aniline hydrogen phthalate as a spraying agent for chromatography of sugars. Nature (Lond.), 164, 443.

Schrager, J. (1961). A revaluation of Glass's method of fractional precipitation of gastric secretion. Gut, $2,37$.

Werner, I. (1953). Studies on glycoproteins from mucous epithelium and epithelial secretions. Acta Soc. Med. upsalien., 58, 1-55,

Wilson, C. M. (1959). Determination of sugars on paper chromatograms. Anal. Chem., 31, 1199-1201. 